\title{
Comunidade na cidade: mídias comunitárias como infraestruturas comunicacionais urbanas ${ }^{1}$
}

\author{
Community in the city: community media as urban \\ communication infrastructures
}

\section{Andrea Meyer Landulpho Medrado}

Professora do Programa de Pós-graduação em Mídia e Cotidiano (PPGMC) e do Departamento de Comunicação Social da Universidade Federal Fluminense. Coordenadora do grupo de trabalho Comunicação Comunitária e Mídia Alternativa da International Association for Media and Communication Research (IAMCR). Co-investigadora internacional da Rede e-Voices Redressing Marginality (Arts and Humanities Research Council, Reino Unido).

\section{RESUMIO}

Este artigo é construído em três etapas: a primeira é predominantemente conceitual e as outras duas são fundamentadas em pesquisa etnográfica (offline e online). Em um primeiro momento, discuto o conceito de "comunidade", situando-o nos debates sobre mídia e cidade. Mesmo reconhecendo que as mídias digitais permitem que os cidadãos adotem dinâmicas de localidade mais fluidas, meu objetivo é demonstrar que as comunidades urbanas continuam ocupando um lugar de destaque nos debates sobre cidades mediadas. Em seguida, este estudo aborda o lugar que as práticas midiáticas ocupam na constituição de comunidades como as favelas, analisando um estudo de caso, o

\footnotetext{
1 Uma versão modificada deste artigo será publicada, ainda em 2019, somente em língua inglesa, no livro "The Routledge Companion to Urban Media and Communication" (no prelo), editado por Zlatan Krajina e Deborah Stevenson.
} 
da escuta da rádio de poste em um bairro em Salvador. Finalmente, o artigo revela como ativistas de favelas no Rio de Janeiro utilizam as redes sociais como infraestruturas comunicacionais urbanas na Maré. $\mathrm{O}$ artigo analisa as maneiras como iniciativas comunitárias offline e online representam recursos simbólicos e materiais aplicados a vidas cotidianas estruturadas pela desigualdade.

Pallavras-chave: Comunidade; Mídia, Cotidiano e Cidade; Mídia Comunitária; Etnografia; Favela.

\section{ABSTRACT}

This article is organised around three main stages. I start presenting the study's conceptual framework, analysing the notion of community and placing it within wider debates on media and mediated cities. I wish to argue that despite the assumption of how media allow citizens to live free from dynamics of locality and community, urban communities remain extremely important for debates about mediated cities. For the other two stages, I have conducted ethnographic research to analyse the role of media practices in processes of community building. In order to achieve this, I have delved into one case study, that of listening to a "lamppost radio" in a neighbourhood in Salvador. Finally, I discuss the ways in which favela activists are using social media as urban communication infrastructures in Favela da Maré. Thus, this article analyses the ways in which community media represent symbolic and material resources in the daily lives of people who have to constantly face inequalities.

Keywords: Community; Media, Everyday Life and City; Community Media; Ethnography; Favela.

\section{RESUMEN}

Este trabajo está construido en tres etapas: la primera es conceptual y las otras dos son basadas en investigación etnográfica. En un primer momento, discuto el concepto de "comunidad", situándolo en los debates sobre medios y ciudad. Si bien reconozco que los medios digitales permiten a los ciudadanos adoptar dinámicas fluidas de localidad, mi objetivo es demostrar que las comunidades urbanas continúan ocupando un lugar destacado en los debates de ciudades mediadas. Luego, este estudio aborda el lugar que ocupan las prácticas de los medios en la constitución de comunidades, analizando un estudio de caso, el de escuchar la radio de poste en un barrio de Salvador. Finalmente, el artículo revela cómo los activistas en Río de Janeiro usan las redes sociales como infraestructuras de comunicación urbana en Maré. Este trabajo analiza las formas en que las iniciativas comunitarias representan recursos simbólicos y materiales aplicados a las vidas cotidianas estructuradas por la desigualdad.

Pallabras-clave: Comunidad; Medios de Comunicación, Cotidiano y Ciudad; Medios Comunitarios; Etnografía; Favela. 


\section{Introdução: visões urbanas da comunidade}

Por uma perspectiva histórica, o conceito de comunidade ocupou um espaço de destaque no pensamento sociológico urbano. Ao revisitar alguns dos debates que surgem em torno desse conceito, Anthony Cohen critica a forma em que alguns sociólogos demonstravam uma percepção de comunidade como se a mesma representasse uma qualidade da vida social intrínseca às sociedades rurais. Seguindo essa linha de pensamento, alguns dos atributos da comunidade incluiriam paroquialismo, tradicionalismo e conservadorismo, assim também como uma dependência da existência de um caráter presencial. Assim, o estar em comunidade incluiria uma qualidade de interação que resultaria das pessoas possuírem "um vasto conhecimento pessoal umas das outras", já que suas relações seriam sustentadas por laços quase inquebráveis de afinidade e comunidade (Cohen, 2001, p. 25). Tal percepção ilustra o legado do trabalho de autores canônicos como Ferdinand Tönnies (1887/1963), que estabeleceu uma distinção entre gemeinschaft, ou comunidade, e gesellschaft, ou sociedade, e Émile Durkheim (1893), que apresentou uma distinção entre solidariedade orgânica e mecânica.

Vale aqui ressaltar que esses modelos, assim também como outros modelos posteriores, como o modelo "Darwinista" da Escola de Chicago, representavam uma resposta ao surgimento da sociedade urbana na virada do século XX. Dessa forma, reconheciam as formas emergentes de associação humana como consequências técnicas da vida em uma sociedade de massa. Portanto, não é surprendeente que, naquele contexto, a ideia de comunidade estivesse relacionada às caraterísticas de sociedades rurais, que contemplavam laços de afeição e aspectos familiares, íntimos, privados. Por outro lado, a sociedade urbana de massa era percebida como sendo anacrônica à solidariedade comunitária. Ela teria assim características 
públicas e racionais, fundamentadas em relações despersonalizadas e caracterizadas pelo processo de especialização dos papéis que as pessoas exercem na sociedade industrial. Assim, para citar Simon Parker, as reflexões subsequentes passaram a ser voltadas para o estabelecimento de definições do que seria e de como deveria ser uma comunidade (Parker, 2004, p. 97).

Surge nesse contexto um debate relevante: até que ponto sentimentos de solidariedade e união podem ser despertados em áreas urbanas densamente povoadas? Em um famoso estudo sobre família e parentesco no leste de Londres, Michael Young e Peter Willmott ([1953], 1992) ofereceram uma resposta positiva a essa questão, defendendo um reconhecimento de um elemento ao qual eles se referiam como a "redescoberta da importância do grupo primário de relações". Para Young e Willmott, a percepção de que as cidades levariam a uma atitude blasé de recolhimento social simplesmente não era consistente com o que eles tinham vivenciado em sua pesquisa com sujeitos da classe trabalhadora londrina (Young e Willmott, 1992: xix, em Parker, 2004. p. 75). Herbert Gans, por sua vez, também acreditava que era possível que um forte sentimento comunitário pudesse prosperar entre populações de regiões centrais urbanas. Assim, poderíamos encontrar na vida urbana qualidades tipicamentes associadas às vilas (Gemeinschaft) (Gans, 1982, em Parker, 2004, p. 77). De fato, Jane Jacobs conseguiu demonstrar que, estando combinada com condições toleráveis de vida, a densidade urbana poderia, em alguns casos, vir acompanhada de diversidade e que esses três elementos - condições toleráveis, diversidade e densidade populacional poderiam se tornar componentes essenciais da vida comunitária urbana (Jacobs, 1992, p 208, em Parks, 2004, p 79-80).

No entanto, para a realidade urbana brasileira, tais perspectivas podem parecer, de certa forma, romantizadas ou até ingênuas. Autores brasileiros como Raquel Paiva, por exemplo, propõem um entendimento mais crítico e político da comunidade. De acordo com essa perspectiva, as pessoas poderão constituir uma comunidade carregada de elementos de solidariedade 
no momento em que assumirem o papel de sujeitos politicamente engajados como forma de oferecer uma resposta urgente e necessária a um processo de rompimento de seus tecidos sociais (Paiva, 1998; Félix et. al, 2017, p. 99).

De qualquer forma, em outras abordagens subsequentes sobre as comunidades urbanas, encontra-se uma tendência de compreender as comunidades emergentes com base em interesses e não necessariamente em localidades compartilhadas. Acredita-se que esse seja um processo de caráter significativamente mediado. Para citar Nicholas Jankowski, "as comunidades podem reunir pessoas que compartilham interesses culturais, sociais ou políticos e esses elementos podem funcionar como princípios organizacionais fundamentais tão válidos como o fato de estarem em áreas geograficamente circunscritas, como aldeias, bairros e cidades (Jankowski, 2002, p. 5).

Este artigo explora os conceitos de "comunidade", "mídia" e "cidade", com uma atenção especial para as práticas de mídia comunitária em espaços urbanos no Brasil. Gostaria aqui de reforçar o argumento central deste artigo: mesmo reconhecendo as múltiplas maneiras em que as mídias digitais permitem que os cidadãos adotem dinâmicas mais fluidas de localidade, as comunidades urbanas continuam assumindo um papel extremamente importante nos debates sobre cidades mediadas. Vale esclarecer que utilizo aqui a escrita em primeira pessoa, já que este é um estilo coerente com a abordagem metodológica etnográfica que fundamenta minha pesquisa.

No texto, também pretendo analisar o papel que as mídias comunitárias podem exercer em processos de construção comunitária, assim também como no sentimento de pertencimento à cidade. Além de servirem para documentar as especificidades comunitárias, as variadas iniciativas offline e online de mídia comunitária podem representar recursos simbólicos e materiais aplicados a vidas cotidianas que costumam ser estruturadas por múltiplas camadas de desigualdade. Para fundamentar meus argumentos, vou utilizar dados de uma pesquisa anterior sobre o papel da rádio comunitária no bairro popular de Pau da Lima, em Salvador (Medrado, 2010), assim também 
como dados de minha pesquisa atual acerca da utilização de mídias sociais por moradores de favelas do Rio de Janeiro para construção de redes de solidariedade e proteção (Medrado, Souza e Cabral, 2018). Por fim, pretendo explorar em profundidade casos em que as mídias urbanas e as mídias comunitárias se mostram interligadas, demonstrando as maneiras em que as mídias comunitárias representam formas importantes de "infra-estruturas comunicacionais urbanas" (Georgiou, Motta e Livingstone, 2016, p. 4-6).

\section{Favela: A Comunidade como Forma de Resistência?}

É de conhecimento geral que uma planta do sertão nordestino deu origem ao termo "favela". Essa raiz etimológica é brevemente retomada aqui porque apresenta uma dimensão simbólica importante. Autoras como Lícia Valladares (2005) nos lembram do quanto, no contexto social brasileiro, as favelas e seus moradores demonstram sua resiliência ao longo da história, enfrentando condições desfavoráveis, a contínua violência de Estado e tentativas recorrentes de erradicá-las. Janice Perlman, por exemplo, ainda em 1976, já abordava as maneiras como as favelas vinham historicamente demonstrando oposição às políticas sociais que envolviam despejos, remoções e limpezas sociais, enfrentando intervenções urbanas marcadas pela arbitrariedade e pelo preconceito (Perlman, 1976). Aqui, as contribuições de Anthony Cohen acerca da comunidade revelam-se úteis. $\mathrm{O}$ autor observa que a consciência da comunidade reside em percepções compartilhadas de fronteiras simbólicas, fronteiras essas que são constitutivas de comunidades, além de serem também constituídas por membros das comunidades por meio da interação (Cohen, 2001, p. 13). Assim, é crucial que sempre comecemos a nos ater aos processos simbólicos de estabelecimento de fronteiras e que nos concentremos na "natureza essencialmente simbólica da ideia de comunidade, uma ideia essencialmente forjada no conceito de fronteira". Em outras palavras, para Cohen, não há comunidade sem que se note uma diferença ensaiada dessa comunidade com relação a outras comunidades. (Cohen, 2001, p. 14). 
Porém, o contexto urbano ainda nos oferece um outro importante desafio ou contradição. Como afirma Golberger, o impulso urbano é comunitário, mesmo que isso se manifeste em escalas e formas distintas. A cidade representaria assim um local tipicamente propício ao florescimento da comunidade, porque sua própria existência estaria condicionada ao papel de oferecer proteção aos seus habitantes. Ao mesmo tempo, moradores de áreas marginalizadas, como favelas, costumam ter vivências muito distintas dessa noção de proteção que deveria se estender igualmente a todos os habitantes da cidade. No lugar da proteção, deparam-se com rejeição, discriminação, segregação e marginalização. Refiro-me aqui a uma definição ampla de marginalização, que descreve a exclusão da participação em diversas esferas da vida social, levando a um estado de fragilidade econômica, cultural e/ou e à privação de direitos (Keung, Li \& Song, 2007).

O sociólogo Loic Wacquant também se volta para a discussão dessa marginalização urbana, colocando-a em um contexto do que chama de "neoguetoização". Ele examina tal fenômeno em áreas economicamente vulneráveis de cidades como Chicago e Paris, argumentando que as populações dessas áreas encontram-se, muitas vezes, em situações de "marginalização avançada". Tal condição é "gerada por uma fragmentação do trabalho assalariado e por uma reorientação das políticas de Estado, que passam a distanciar-se dos princípios do Estado de bem-estar social e a mover-se em direção às compulsões do mercado e ao reforço das desigualdades" (Wacquant, 2014, p. 47). Nas próximas seções deste artigo, analisarei os impulsos comunitários como formas de proteção em contextos urbanos no Brasil. Também discutirei processos de formação comunitária como mecanismos de resistência à opressão vinda de um Estado marcado por políticas neoliberais e autoritárias e que também adota diversas políticas de vigilância.

\section{0 que faz (d)a mídia comunitária?}


O debate que surge acerca da necessidade do estabelecimento de definições para a mídia comunitária é extenso e complexo (Howley, 2005). Como o pesquisador britânico Peter Lewis (2006) observou, a adoção de diferentes termos é dependente dos diversos contextos históricos e geográficos em que a mídias comunitárias se fazem presentes. Alguns exemplos de termos e contextos incluem: a "TV de acesso público" (public access TV) nos Estados Unidos e Canadá (Berrigan, 1977), “as rádios de mineiros" na Bolívia (O’Connor, 1990) e os comunicadores populares no Brasil (Gianotti, 2016).

No entanto, apesar dessa grande variedade de contextos e experiências, surgem alguns pontos em comum: a) essas são iniciativas dirigidas a públicos específicos, nomeadamente as comunidades em que estão localizadas ou para as quais se dirigem; e b) elas costumam ser caracterizadas por menores escalas de atuação e abrangência (quando colocadas em contraste com a grande mídia convencional). Além disso, em alguns casos, como ocorre com as rádios comunitárias multiculturais na Europa, há uma maior pluralidade de pontos de vista do que se pode encontrar na mídia mainstream. Salvatore Scifo (2016), por exemplo, conduziu uma pesquisa sobre como as rádios comunitárias no Reino Unido foram introduzidas como sendo pertencentes a um terceiro setor, em contraste com o setores público e comercial. Vale notar que, naquele país, os níveis de imigração permanecem significativos. Como Scifo sugere, uma das principais preocupações da rádio comunitária no Reino Unido tem sido a de atender às necessidades de uma sociedade culturalmente diversificada. 0 autor estudou casos de rádios comunitárias em diversas regiões, como a All FM, uma estação de rádio sediada em Manchester que tinha como público-alvo a população de Ardwick, uma área de habitação social com um alto número de refugiados; a população de Longsight, que era conhecida por sua economia local próspera com pequenas e médias empresas asiáticas; e a população de Levenshulme, que também era conhecida por sua diversidade cultural (Scifo, 2016, p. 217). A fim de cumprir esses propósitos multiculturais, as estratégias da rádio All FM incluíam: 
- Ter em sua grade de programação uma ampla variedade de músicas asiáticas, africanas, irlandesas e afro-caribenhas;

- Ter em sua grade de programação programas em línguas estrangeiras, que incluíam programas em somali, persa e caxemira, com expressivos números de ouvintes no Reino Unido e em seus países de origem (All FM, 2004, p. 26-27, em Scifo, 2016, p. 218)

Entretanto, administrar uma estação comunitária multicultural traz muitos desafios. Scifo observa, por exemplo, que

o senso de comunidades de interesse - ou seja, comunidades estruturadas em torno de grupos étnicos, faixas etárias ou preferências por gênero musical mostrava-se, sem dúvida, mais proeminente do que o senso de comunidade de lugar. Dessa forma, os ouvintes frequentemente sintonizavam programas especializados nas chamadas músicas étnicas.

Como resultado, poucos ouvintes pareciam ouvir a programação da All FM de forma contínua durante todo o dia (Scifo, 2016, p. 216).

Aqui, um entendimento dos motivos pelos quais os ouvintes sintonizam a rádio comunitária é importante para uma melhor compreensão das dinâmicas da comunicação nas relações entre as comunidades e suas mídias. Vale questionar: que lugar as práticas midiáticas ocupam na constituição de comunidades como as favelas? A seguir, apresentarei uma discussão fundamentada em meu estudo etnográfico da recepção de uma rádio de poste em Pau da Lima, um bairro popular localizado em Salvador. Esse caso é particularmente relevante porque ilustra uma forte presença sensorial e material da rádio nos espaços urbanos e ao ar livre do bairro. Também explico que, mesmo sem representar uma rádio em seus aspectos técnicos de transmissão por radiodifusão, já que consiste em um sistema de alto-falantes posicionados em postes nas ruas, partindo de uma perspectiva etnográfica, a rádio de poste é considerada uma rádio comunitária pelos moradores.

\section{A radio de poste e sua comunidade urbana}


0 Pau da Lima é um bairro popular ${ }^{2}$ com aproximadamente 25.000 habitantes (IBGE, Censo Demográfico 2010), localizado no chamado miolo central de Salvador, na Bahia. Salvador, por sua vez, é uma cidade com população estimada em de 2.8 milhões de habitantes (IBGE, 2018) ${ }^{3}$. Localizada em Pau da Lima, a Rádio de Poste Pop Som foi fundada em 1998 pelo morador Elson Simão da Rocha ${ }^{4}$. A rádio possuía 22 alto-falantes em postes situados em locais movimentados, como pontos de ônibus, mercados e igrejas. Mesmo sabendo que a programação não era transmitida através das ondas do rádio, mas sim "gritada" através de alto-falantes, os moradores do Pau da Lima frequentemente se referiam à rádio de poste como a "rádio comunitária do Pau da Lima", como podemos perceber na fala da jovem moradora Ana Cláudia 5 :

É uma radio comunitária porque a "Pop Som" aborda problemas muito comuns em Pau da Lima, como a questão de como prevenir a dengue. Eles sabem que esse é um problema que nos aflige e nós sabemos disso também porque moramos aqui nossa vida inteira. Falamos a mesma língua. Eles falam como a gente. (Entrevista, 06/12/2007)

Mesmo consistindo de alto-falantes presos em postes, a radio Pop Som contribuía para fomentar um sentido de pertencimento entre os moradores. Para Cleméncia Rodriguez, essa é uma característica central da mídia comunitária, que implica em "tornar-se o narrador de sua própria história, reconquistar sua

\footnotetext{
${ }^{2}$ Autores como Antonio Mateus de C. Soares oferecerem uma explicação para a segmentação do espaço urbano em Salvador, dividido em "territórios populares" e "territórios abastados". Os territórios abastados da cidade incluem bairros tradicionais como Canela, Corredor da Vitória, Graça, assim como a maioria dos bairros que margeiam a Orla Atlântica da cidade. Esses territórios representam o que poderíamos considerar como os da cidade formal, a cidade legal, possuidora de equipamentos urbanos e da atenção dos órgãos públicos. Já os "territórios populares" são aqueles compreendidos como os espaços informais da cidade, habitados, em sua maioria, por negros, pobres e desempregados e constituídos pelas áreas situadas ao norte, ao centro e ao oeste de Salvador (Soares, 2006, p. 20)

${ }^{3}$ No ultimo censo realizado pelo IBGE, em 2010, a população de Salvador consta com sendo de mais de 2.6 milhões de pesssoas (IBGE, 2010).

${ }^{4}$ Todos os nomes dos entrevistados aqui citados correspondem a seus nomes reais, embora eu tenha, em alguns casos, omitido seus sobrenomes. Para isso, obtive o consentimento informado dos participantes. Os dados tomam como base meus diários de campo etnográficos, mas as citações diretas são provenientes de entrevistas gravadas e depois transcritas com os participantes da pesquisa.

${ }^{5}$ No período correspondente à pesquisa de campo, Ana Cláudia tinha 22 anos.

${ }^{6}$ Este traballho de campo se deu durante minha pesquisa de doutorado. Embora os dados não sejam recentes, acredito que as observações etnográficas acerca da escuta da rádio de poste ainda se apliquem aos dias atuais. Em pesquisas etnográficas mais recentes, em 2017 e 2018, em favelas do Rio de Janeiro, no Complexo da Maré, também pude verificar a ampla presença de rádios de poste, assim como seu papel na vida cotidiana das pessoas.
} 
própria voz, reconstituir o auto-retrato de sua própria comunidade e de sua própria cultura" (Rodriguez, 2001, p. 3).

Entretanto, outras opiniões, como a de Dona Dalva, 52 anos ${ }^{7}$, que morava perto de um dos postes com alto-falante, refletiam algumas da tensões envolvidas na audiência da rádio:

Às vezes, eles tocam músicas chatas e eu tenho que ouvir. Fazer o que? Mas não posso negar que eles estejam abertos à comunidade porque estão, sim. Meu filho participa de um grupo de teatro comunitário e os apresentadores da rádio sempre fazem o que podem para promover o grupo. Isso é muito bom. (Visita, diário de campo, 03/11/2007)

Os comentários de Dona Dalva parecem contradizer algumas das perspectivas teóricas acerca do papel e dos processos envolvidos na produção de rádio comunitária. Alguns autores, por exemplo, destacam como a rádio comunitária precisa promover processos democráticos de produção de conteúdo com níveis significativos de participação das comunidades envolvidas (Hochheimer, 1993). No entanto, a experiência da moradora, em alguns momentos, não parece demonstrar uma grande natureza democrática. Morando perto de um dos postes com alto-falantes, ela não tinha outra escolha a não ser ouvir a programação. Além disso, ela não demonstrava estar muito interessada em participar da produção de conteúdos para a rádio. Portanto, diante da não tão democrática natureza do ato de escutar à radio de poste, surge a necessidade de retomar uma questão inicial importante: o que fazia com que a rádio de poste cumprisse o papel de rádio comunitária?

Minha pesquisa etnográfica, que consistiu em visitas diárias a 9 famílias selecionadas através de contatos no Pau da Lima (cinco vezes por semana) durante três meses (outubro, novembro e dezembro) indicou que o senso de comunidade estava intimamente ligado a uma questão de presença nas ruas e espaços urbanos coletivos. Aqui, vale ressaltar que apesar dessa não ser uma pesquisa recente, seus resultados ainda podem se aplicados ao papel que mídias comunitárias urbanas exercem na constituição comunitária em cidades

\footnotetext{
${ }^{7}$ Em 2007, durante o período da pesquisa de campo.
} 
brasileiras. De fato, ao realizar nova pesquisa etnográfica de campo, desta vez no Rio de Janeiro, em 2018 e 2017 (que será discutida na próxima seção do artigo), pude observar a vasta presença de alto-falantes em áreas do Complexo da Maré, como, por exemplo, na Rua Teixeira Ribeiro. Assim, guardadas as devidas (e muitas) distinções de contexto entre o Pau da Lima e a Maré, acredito que essa pesquisa etnográfica ainda sirva de embasamento para ilustrar o importante papel que as mídias comunitárias exercem em contextos urbanos contemporâneos.

Para ilustrar meu argumento anterior acerca da presença urbana, pública e coletiva da rádio de poste, durante a pesquisa etnográfica foi possível perceber que os moradores ouviam a rádio de poste como algo inseparável das rotinas do bairro. Em termos espaciais, os alto-falantes estavam localizados em pontos estratégicos, onde podiam ser facilmente vistos e ouvidos. Pessoas de diferentes faixas etárias sabiam identificar a localização do estúdio central da rádio e pareciam apreciar o fato de poder contar com portas "sempre abertas". Como foi sugerido por Dona Dalva, havia uma ampla utilização dos recursos da rádio por grupos comunitários, como era o caso do grupo de teatro, que mesmo sem ter uma participação direta nos processos de produção da programação, tinha fácil acesso aos apresentadores e funcionários da rádio, que eram receptivos às suas demandas. É interessante notar que para os moradores esse fácil acesso parecia ser mais característico do aspecto comunitário da rádio do que a participação na programação em si. Durante minhas visitas às famílias no Pau da Lima, pude, algumas vezes, testemunhar as idas de Gustavo, filho de Dona Dalva, ao estúdio. Nessas idas, ele levava pedaços de papel com informações sobre apresentações do grupo de teatro, que entregava a um dos apresentadores da rádio, que ou as lia imediatamente, ou as colocava sobre a mesa para ler depois (Medrado, 2010, p. 146). Assim, embora as práticas da rádio de poste não possam ser caracterizadas como sendo inteiramente democráticas em termos normativos, evidenciava-se o quanto a rádio de poste ganhava importância e contribuía para uma construção comunitária, que se dava através de uma presença sonora cotidiana na comunidade. 
Ao mesmo tempo em que a presença da rádio de poste no cotidiano dos moradores parecia fortalecer um sentimento de pertencimento às ruas da vizinhança, a rádio também transformava a natureza da experiência, ampliando a paisagem sonora urbana daquele bairro popular. Outro jovem morador, Ronei, ilustra bem essa questão, ao se referir à rádio de poste como sendo responsável por estabelecer uma "trilha sonora nas ruas e no cotidiano":

\begin{abstract}
Eu costumava escutar umas músicas tranquilas quando estava voltando da escola ano passado, tipo umas $17 \mathrm{~h}$ ou $18 \mathrm{~h}$. Eles tinham um programa de lentinhas do fim da tarde ou alguma coisa assim. A música era calma, várias vezes tocava MPB, eu me sentia bem voltando pra casa depois de um dia agitado. (Visita, diário de campo, 10/11/2007)
\end{abstract}

Dessa forma, em um ambiente marcado pelo alto volume dos sons do trânsito e do comércio, uma música calma demarcava o fim do dia agitado de Ronei, ajudando-o com sua transição da escola para a casa e da rua para o seu ambiente doméstico. Essa observação ecoa algumas das ideias de Paddy Scannell (1996) acerca de uma repetitividade ontologicamente tranquilizadora que caracteriza o papel da rádio no cotidiano dos ouvintes. Parece-nos, portanto, que ao tocar uma música suave ao final de um dia agitando, no momento em que crianças e jovens voltavam pra casa, a rádio Pop Som demonstrava um bom nível de conhecimento das rotinas diárias das pessoas que se movimentavam pelo bairro. Se lembrarmos que as reflexões de Scannell foram feitas com base na presença da rádio pública nos lares britânicos, a diferença aqui é que a cotidianidade da Pop Som não se referia a ambientes domésticos e privados, mas sim a um sentimento de familiaridade praticado nas ruas através de seus altofalantes. Por sua vez, isso parecia confirmar algumas das percepções dos participantes de minha pesquisa: para que possa ser percebida como comunitária, a rádio precisava conhecer intimamente e, mais que isso, ecoar os ritmos e características da vizinhança.

\title{
Mídias comunitárias como infraestruturas comunicacionais na cidade
}


Nas seções anteriores, este artigo analisou as contribuições da rádio de poste na construção comunitária de um bairro popular, Pau da Lima, em Salvador. Já nesta seção, discutirei como moradores de áreas marginalizadas do Rio de Janeiro estão utilizando as mídias sociais como um recurso cotidiano em um contexto urbano pós-olímpico.

No ano de 2018, o Rio de Janeiro já lidava com as consequências do que muitos atribuíam a políticas urbanas mal pensadas, implementadas, principalmente, ao longo da década de 2010 com o intuito de preparar a cidade para a Copa do Mundo de 2014 e as Olimpíadas de 2016. De forma resumida, essas políticas resultaram em consequências como: a) processos de gentrificação ${ }^{8}$ em áreas de favelas, principalmente as localizadas na Zona Sul da cidade, com o aumento de preços e a expulsão de moradores que não tinham mais condições de arcar com os altos custos nessas áreas (a chamada remoção branca); b) dinâmicas de segregação com a construção de muros e paredes, como os construídos ao longo da Favela da Maré na Linha Vermelha para impedir que os visitantes que chegavam ao Rio enxergassem as desigualdades sociais da cidade; c) uma militarização da vida cotidiana com programas de "pacificação das favelas" e intervenções militares em diversas favelas (Comitê Popular da Copa e das Olimpíadas, 2015)

Algumas questões importantes permeavam essa remodelagem do Rio de Janeiro para os megaeventos, projetando a cidade de forma a estar encaixada em um imaginário global de paisagens maravilhosas e atrações exóticas. De fato, há uma vasta literatura que aborda as maneiras como as imagens das cidades sede são centrais aos estudos dos megaeventos (Freitas et. al 2016). Na prática, os espaços urbanos são remodelados e reconstruídos para que possam articular algumas ideias projetadas em espaços materiais. 0 problema é que essas

\footnotetext{
${ }^{8}$ Alguns autores, como Luís Mendes, têm se debruçado sobre o conceito de "gentrificação", analisando como o mesmo está associado a um discurso de "regeneração urbana". Dessa forma, a gentrificação funciona como um mecanismo de legitimação do poder instituído com o intuito de mobilizar grande investimento público que, ao invés de ser direcionado ao auxílio das populações vulneráveis, funciona como subsídio aos mais privilegiados como instituições financeiras, grandes grupos económicos e de construção civil, etc. (Mendes, 2008, p.2).
} 
transformações nem sempre atendem às necessidades dos moradores das cidades sede. Questões semelhantes ocorreram em outras cidades, como Londres, que sediou as Olimpíadas em 2012. Autores como Phil Cohen, for exemplo, entrevistaram moradores em Newham, no leste londrino, onde ele descobriu que os moradores mostravam-se bastante preocupados com a mudança de perfil do bairro com a chegada de moradores de classe média alta (Cohen, 2013, p. 311- 312).

No caso do Rio de Janeiro, houve grande ansiedade com relação às políticas de segurança do Estado para obter maior controle das favelas. A intervenção mais marcante, nesse sentido, foi a implantação das Unidades de Polícia Pacificadora (UPPs), um programa que se iniciou em 2008. Em seus primeiros anos, entre 2008 e 2010, o programa de pacificação recebeu elogios na grande mídia e teve uma percepção positiva entre os moradores dos bairros de classe média e alta do Rio de Janeiro. A proposta inicial era retirar das mãos de facções criminosas o controle das favelas, "reconquistando-as" para o poder do Estado (Carneiro, 2010). No entanto, a confiança no programa caiu rápida e vertiginosamente com a proliferação de um grande número de alegações de abusos de direitos humanos por parte dos policiais. (Watts, 2014). De acordo com a Comissão de Direitos Humanos do Rio de Janeiro, as violações incluíam violência policial e assédio moral aos moradores, além de frequentes invasões de domicílios nas favelas. Além disso, as políticas de segurança pública eram (e seguem sendo) conduzidas por uma filosofia de militarização do cotidiano. De acordo com Júlia Valente (2014), esse termo se refere à utilização de táticas e pessoal militares que percebem a favela como uma espécide de território inimigo, criminalizando suas populações e, em especial, a população favelada jovem e negra.

Na próxima seção deste artigo, analisarei um outro estudo de caso, discutindo como um grupo de ativistas de favelas está se apropriando das mídias sociais como um recurso cotidiano para que moradores possam viver e sobreviver em uma cidade pós-olímpica e militarizada. Desde a sua criação, em

\section{2}

Dossiê Novas Faces do Poder - http://revistaecopos.eco.ufrj.br/ - ISSN 2175-8689 - v. 22, n. 2, 2019. 
2014, a página Maré Vive (https://www.facebook.com/Marevive) já obteve mais de 140 mil curtidas e se descreve como um "canal de mídia comunitária feito de forma colaborativa". Minha pesquisa de campo incluiu entrevistas em profundidade e observações etnográficas online e offline ao longo de $2017^{9}$, com a participação de uma bolsista de iniciação científica. Ela demonstra que a Maré Vive adota um perfil de mídia comunitária à medida em que trabalha com problemas que são específicos da Maré, mas que também se relacionam com questões sociais brasileiras e globais mais amplas, como desigualdade social, racismo e violência policial. Como os estudos urbanos frequentemente apontam, a vizinhança continua representando a unidade espacial e o princípio organizacional básico para as comunidades urbanas. Historicamente, o bairro do Harlem, em Nova Iorque, epitomiza esss questões. Como Steve Pile argumenta, o Harlem passou a ter um duplo significado: o bairro representa, ao mesmo tempo, um poderoso símbolo global da cultura urbana negra, constituindo "uma cidade global dentro de uma cidade global", e um bairro que, historicamente, sofreu muitas deprivações econômicas e sociais em Nova Iorque (Pile et. al, 2005, p. 21).

Já no contexto latino americano, pesquisadores revelam o quanto as favelas sofreram e ainda sofrem de estigmatizações territoriais (Mooney, 2005, p. 75), sendo consideradas abrigos para as classes sociais mais perigosas e vistas como fontes de medo e ansiedade para as cidades (Valladares, 2005; Perlman, 1976). Desde a década de 1930, autores como Agache (1930) se referiam às favelas de forma pejorativa, criticando sua gente e suas casas "sem ordem" ou "organização", que estariam levando à constituição de comunidades que jamais

\footnotetext{
${ }^{9}$ Realizamos um acompanhamento diário das postagens na fan page no Facebook Maré Vive de janeiro a dezembro de 2017. Esse acompanhamento vem sendo complementado por notas de trabalho de campo, escritas com base no que observamos na fan page e mantendo o espírito reflexivo, detalhado e subjetivo que a abordagem da antropologia digital nos oferece. Nessas capturas regulares de conteúdo, temos analisado, a cada mês, os quatro posts com maior número de reações, o que inclui o número de curtidas, representadas pelo ícone do polegar, dando um sinal de positivo; "amei", representado pelo ícone do coração; "raiva", representada pelo emoticon com expressão indignada; "tristeza", representada pelo emoticon com uma lágrima; e "risada", representada pelo emoticon que dá uma gargalhada. Em paralelo às observações etnográficas, também estamos realizando uma contextualização dos dados obtidos online, produzindo notas de trabalho de campo sobre os eventos políticos, culturais e sociais relacionados às postagens coletadas. 0 material vem sendo organizado em categorias, de acordo com temas (por exemplo: violência policial, eventos culturais, comentários políticos etc.)
} 
poderiam ser "funcionais". Embora atualmente essas desqualificações não tenham desaparecido do discurso público, antropólogos como William Mangin (1967) e Janice Perlman (1976) demonstraram o contrário: as favelas representam, na verdade, soluções para difíceis problemas sociais, oferecendo opções de moradia dentro do poder aquisitivo de migrantes e populações desfavorecidas em áreas urbanas. Essa perspectiva representou uma mudança de paradigma, que nos permitiu compreender as favelas como organismos sociais coesos, organizados, além de locais onde a solidariedade e o espírito de comunidade podem, sim, florescer.

A fim de transmitir uma imagem de ordem e organização para o público internacional, muitas políticas de segurança concentraram-se em submeter os moradores das favelas a um regime de vigilância constante. Renata Souza (2017) é uma das autoras que se referem a esse fenômeno como sendo caracterizado por uma "militarização do cotidiano", que afeta todas as esferas da vida dos moradores da Maré e de outras favelas. Localizada na Zona Norte do Rio, a Maré recebe a denonimação de "complexo de favelas", incluindo 16 favelas em seu território. Com o objetivo de tornar o complexo da Maré um local mais seguro, em abril de 2014, foram enviadas 2.7000 tropas do exército, que permaneceram ali até junho de 2015 (Roque, 2014). Durante esse período, ocorreu um número significativo de violações de direitos humanos. Após a saída do exército, o Governo anunciou, mas não implementou, o plano de levar uma UPP para a Maré. Ainda assim, passaram a ocorrer diversas operações policiais, que se tornaram temidas pela exposição de moradores inocentes, muitas vezes crianças e idosos, a intensos tiroteios, resultando no fechamento de escolas, na interrupção das vidas cotidianas das pessoas e até em mortes. Criada como uma resposta a esse contexto de militarização, a página Maré Vive costuma publicar diversas atualizações diárias sobre as condições de segurança em várias áreas da Maré, especialmente quando estão ocorrendo operações policiais. Muitas postagens buscam atualizações sobre as condições de segurança, gerando informações que são rápida e continuamente atualizadas nos comentários por moradores que se encontram em diversas áreas da Maré. Dessa forma, moradores que estão saindo 
de casa ou voltando para casa podem checar a página para evitar as áreas mais perigosas, como está ilustrado na postagem abaixo, que gerou 46 comentários.

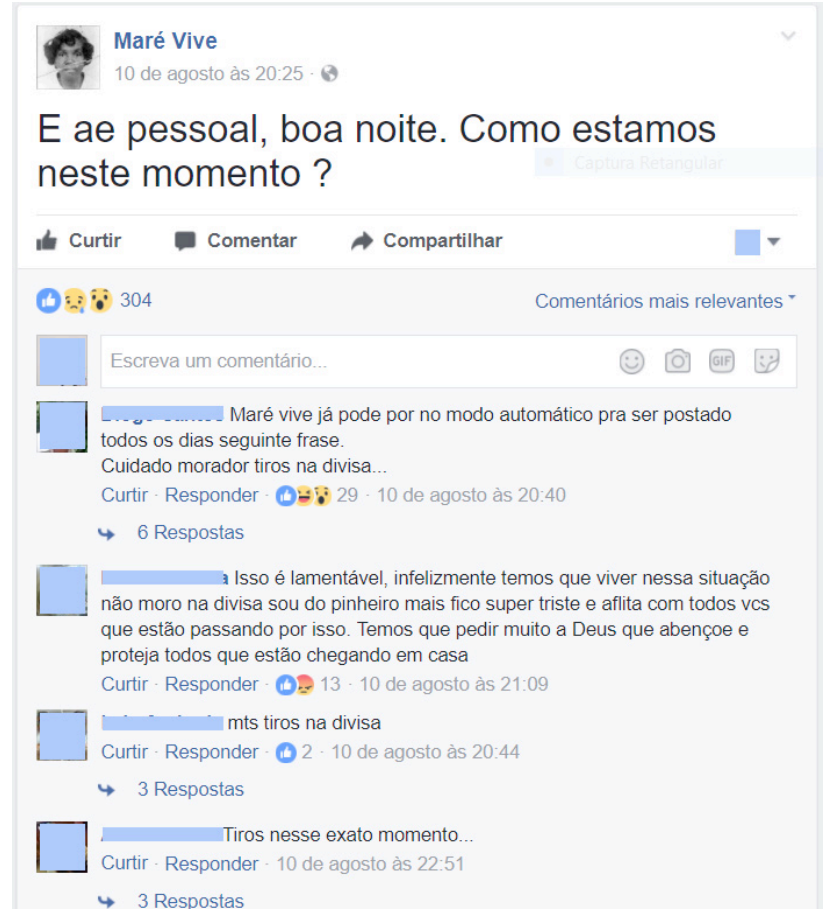

Figura 1: Captura de tela, Página Maré Vive, 10 agosto de 2017

Essa postagem, assim também como os comentários que gerou, ilustram uma espécie de auto-organização comunitária que utiliza as redes sociais como instrumentos de proteção. Myria Georgiou, Wallis Motta e Sonia Livingstone discutem a importância das infraestruturas comunicacionais no cotidiano das cidades mediadas. As autoras afirmam que essas infraestruturas podem fornecer instrumentos simbólicos e materiais que auxiliam os moradores na organização e administração de suas vidas cotidianas. Esses recursos podem então ser “convocados, mobilizados e apropriados pelos moradores locais para gerar o desenvolvimento de redes de apoio e desenvolvimento urbano" (Georgiou, Motta e Livingstone, 2016, p.7). Dessa forma, como minha pesquisa sugere, as mídias sociais passam a oferecer caminhos digitais para que os moradores de comunidades marginalizadas possam lidar com questões complexas de segurança nos espaços em que transitam e vivem. As mídias sociais passam 
então a representar "infraestruturas digitais comunicacionais", que ocupam um papel crucial, não apenas para abordar questões de pertencimento e participação na comunidade, mas também para oferecer recursos vitais para a sobrevivência em espaços marcados pela desigualdade e pelo conflito urbano.

Com a Maré Vive, percebe-se que os moradores da Maré utilizam as redes sociais para fortalecer um sentimento de pertencimento à comunidade através da resistência à militarização cotidiana de seus espaços. Em termos teóricos, define-se resistência a partir da habilidade de desafiar estruturas de poder tradicionais, como as governamentais, religiosas e institucionais, assim também como as estruturas hegemônicas de poder, na concepção Gramsciana. A pesquisa demonstra que, no contexto da favela, a resistência se refere às habilidades de mobilização de recursos comunicacionais para lidar com os muitos desafios que uma vida cotidiana militarizada oferece. Assim, através do compartilhamento de informações e demonstrações de cuidado e resiliência, as pessoas podem responder a uma dura realidade, marcada pela falta de respeito a direitos fundamentais e pela falta de apoio por parte de instituições governamentais.

\section{Considerações finais}

A noção de comunidade ainda retém uma alta relevância para os debates acerca das cidades mediadas. Mesmo tendo sido realizada em períodos distintos, minha pesquisa etnográfica nas favelas indica que a noção de comunidade ainda é altamente significativa, particularmente em um contexto de segregação, marginalização e opressão que, historicamente, como demonstrei, sempre afetou as cidades brasileiras. As dimensões afetivas da comunidade, algo que pude observar tanto nas ruas do Pau da Lima como nos espaços online do Maré Vive, manifestam-se de forma muito próxima a uma noção de resistência. Dessa forma, os moradores utilizam diversas mídias online e offline como recursos para gerenciar melhor a vida cotidiana, afirmando suas identidades como cidadãos 
legítimos que pertencem e realizam contribuições sociais, culturais e econômicas imprescindíveis para a cidade.

Ao mesmo tempo, as mídias parecem alterar a natureza da vida em comunidade. Isso ocorre quando incorporam uma maior pluralidade de vozes, como é o caso da rádio All FM, em Manchester. Isso também ocorre quando as mídias ampliam as dimensões de um bairro com o transporte de suas características e ritmos peculiares para as paisagens sonoras, como era o caso da Rádio Pop Som em Salvador, ou para espaços online nas redes sociais, como é o caso da Maré Vive, no Rio de Janeiro. Tanto no Pau da Lima como na Maré, os alto-falantes e as postagens de Facebook ajudaram a criar bairros e vizinhanças ampliadas, demonstrando as habilidades de ambos para ajudarem a administrar questões cotidianas simples, como a volta da escola para casa, no primeiro caso, e complexas, como se proteger da violência urbana, no segundo caso. As mídias comunitárias representam, assim, formas de infraestruturas comunicacionais urbanas, não só de vivência, mas, também e principalmente, de sobrevivência.

\section{Referências bibliográficas}

AGACHE, Alfred. Cidade do Rio de Janeiro: Extensão, Remodelação, Embelezamento, Rio de Janeiro: Prefeitura do Distrito Federal, 1930.

BERRIGAN, Frances (Ed.). Access: Some Western Models of Community Media, Paris: UNESCO, 1977.

BRZOZOWSKI, Jan. International Migration and Economic Development. Estudos Avançados 26 (75), 2012.

CARNEIRO, Júlia. "UPPs Completam Dois Anos com Aprovação Alta e Planos de Expansão". BBC Brasil, 20 de dezembro de 2010 Disponível em http://www.bbc.com/portuguese/noticias/2010/12/101216_rio_upps_2anos_jc : Acesso em 15 abril 2019

COHEN, Phil. On the Wrong Side of the Track? East London and the Post Olympics, London: Lawrence and Wishart, 2013.

COHEN, Anthony. The Symbolic Construction of Community, London and New York: Routledge/Taylor \& Francis e-Library, 2001.

COMITÊ POPULAR DA COPA E DAS OLIMPÍADAS. "Dossiê do Comitê Popular da Copa e das Olimpíadas: Olimpíada Rio 2016, os Jogos da Exclusão", 2015. (acesso em 10 abril, 
2019:

http://www.childrenwin.org/wp-content/uploads/2015/12/DossieComit\%C3\%AA-Rio2015_low.pdf)

DURKHEIM, Émile. De La Division Du Travail Social: Étude Sur L'Organisation Des Sociétés Supérieures. Paris: Alcan, 1983.

FÉLIX, Carla, FRAGOSO, Mariana \& COSTA, Andrew. "Entre o Comunitário, o Popular e o Contrahegemônico: Limites Teóricos e Aproximações Cotidianas", Questões Transversais Revista de Epistemologias da Comunicação, 5 (10): 98 - 106, 2017.

FREITAS, Ricardo, LINS, Flávio \& CARMO DOS SANTOS, Maria Helena. Megaeventos, Comunicação e Cidade. Rio de Janeiro: CRV, 2016.

GANS, Herbert. The Urban Villagers. Group and Class in the Life of Italian-Americans, 2nd edn, London: The Free Press/Collier Macmillan Publishers, 1982.

GEORGIOU, Myria. Media and the City: Cosmopolitanism and Difference, Cambridge, Malden, MA: Polity Press, 2013.

GEORGIOU, Myria, MOTTA, Wallys \& LIVINGSTONE, Sonia. Community Through Digital Connectivity? Communication Infrastructure in Multicultural London: Final Report, The London School of Economics and Political Science, London, UK (acesso 05 abril 2019: http://eprints.lse.ac.uk/69587/), 2016

GIANOTTI, Claudia. Experiências em Comunicação Popular no Rio de Janeiro Ontem e Hoje: Uma História de Resistência das Favelas Cariocas. Núcleo Piratininga de Comunicação, Fundação Rosa Luxemburgo, 215 p, 2016.

GOLDBERGER, Paul. (2001) "Cities, Places and Cyberspace", Paul Goldberger Website (acesso 05 abril 2019): http://www.paulgoldberger.com/speeaches.php?speech=berkeley\#articlestart)

HOCHHEIMER, John. "Organising Democratic Radio: Issues in Praxis", Media, Culture and Society 15 (3): 473-86, 1993.

HOWLEY, Kevin. Community Media: People, Places and Communication Technologies, Cambridge: Cambridge University Press, 2005.

JACOBS, Jane. The Death and Life of Great American Cities, New York: Vintage Books, 1992.

JANKOWSKI, Nicholas \& PREHN, Ole (eds.) (2002). Community Media in the Information Age: Perspectives and Prospects, Cresskill, NJ: Hampton Press.

KEUNG WONG, Daniel Fu e YING LI, CHANG E SONG, He Xue. "Rural Migrant Workers in Urban China: Living a Marginalised Life", International Journal of Social Welfare 16 (1): 32-40, 2007.

LEWIS, Peter. “Community Media: Giving a Voice to the Voiceless," in: Peter

LEWIS \& Susan JONES (eds.), From the Margins to the Cutting Edge: Community Media and Empowerment, Cresskill, NJ: Hampton Press, pp. 13-39, 2006. 
MANGIN, William. "Latin American Squatter Settlements: A Problem and a Solution", Latin American Research Review 2(3): 65-98. (acesso 05 abril 2019: http://links.jstor.org/sici?sici=00238791\%28196722\%292\%3A3\%3C64\%3ALASSAP\% 3E2.0.C0\%3B2-D), 1967.

MEDRADO, Andrea. The Waves of the Hills: Community and Radio in the Everyday Life of a Brazilian Favela (tese de doutorado). University of Westminster (acesso 05 abril 2019: http://westminsterresearch.wmin.ac.uk/8944/1/A_MEDRADO.pdf), 2010.

MEDRADO, Andrea, SOUZA, Renata \& CABRAL, Taynara. "Ativismo Digital de Favelas Como Formas de Infraestrutura Comunicacional Urbana". In: BRAIGHI, Antonio Augusto, LESSA, Cláudio \& CÂMARA, Marco Túlio (Orgs.). Interfaces do Midiativismo: DoConceito à Prática, Belo Horizonte: CEFET-MG, 2018, p. 278-299.

MENDES, Luís. "Gentrificação e a Cidade Revanchista: que lugar para os Movimentos Sociais Urbanos de Resistencia?", Fórum Sociológico 18: 1-13. (acesso 02 setembro 2019: https://journals.openedition.org/sociologico/226), 2008.

MOONEY, Gerry. "Urban Disorders," in Steve PILE, Cristopher BROOKES \& Gerry MOONEY (eds.) Understanding Cities: Unruly Cities?, London and New York: Routledge/Taylor \& Francis e-Library, pp. 49-95, 2005.

O'CONNOR, Alan. The Miners' Radio Stations in Bolivia: A Culture of Resistance'. Journal of Communications, 40 (1), pp. 102-110, 1990.

PAIVA, Raquel. O Espírito Comum: Comunidade, Mídia e Globalismo, Rio de Janeiro: Vozes, 1998.

PARKER, Simon. Urban Theory and the Urban Experience: Encountering the City, London and New York: Routledge, 2004.

PERLMAN, Janice. The Myth of Marginality: Urban Poverty and Politics in Rio de Janeiro, Berkeley, London: University of California Press, 1976.

PILE, Steve, BROOK, Cristopher \& MOONEY, Gerry. Unruly Cities? London and New York: Routledge/Taylor \& Francis e-Library, 2005.

RODRIGUEZ, Cleméncia. Fissures in the Mediascape: An International Study of Citizens' Media, Cresskill, NJ: Hampton Press, 2001.

ROQUE. Átila. The military occupation of Maré ahead of Brazil's World Cup. Amnesty International Brazil, 08/04/2014. (acesso 05 abril 2019: https://www.amnesty.org/en/latest/campaigns/2014/04/the-military-occupation-ofmare-ahead-of-brazils-world-cup/)

SCANNELL, Paddy. Radio, Television and Modern Life, Oxford: Blackwell, 1996.

SCIFO, Salvatore. The Origins and Development of Community Radio in Britain Under New Labour (1997-2007). Ph.D. Thesis, University of Westminster, 2016. (accessed 10 abril, 2019: http://westminsterresearch.wmin.ac.uk/12210/1/Salvatore_SCIFO.pdf)

SOARES, Antonio Mateus de C. "Territorialização e Pobreza em Salvador”, Estudos 
Geográficos, Rio Claro, 4(2): 17-30 (acesso 02 setembro 2019:

https://www.periodicos.rc.biblioteca.unesp.br/index.php/estgeo/article/view/

202/175), 2006

SOUZA, Renata. O Comum e a Rua: Resistência da Juventude Frente à Militarização da Vida na Maré (Ph.D. Thesis), Universidade Federal do Rio de Janeiro, 2017.

TONNIES, Ferdinand. Community and Society, London: Harper \& Row, 1963.

VALLADARES, Lícia. A Invenção da Favela: Do Mito de Origem a Favela.com $1^{\text {st }}$ ed, Rio de Janeiro: Editora FGV, 2005.

VALENTE, Júlia. UPPs: Observações Sobre a Gestão Militarizada de Territórios Desiguais. Revista Direito e Práxis, 5 (9): 207-225, 2014.

WACQUANT, Loic. Ghettos and Anti-Ghettos: The New Regime of Urban Marginality in the 21st Century. City and Social Inclusion Monograph, International Association of Educating Cities, 2014.

WATTS, Jonathan. "Brazil to Order Army Into Rio Slums as Violence Escalates Before World Cup," The Guardian, 24 março 2014. (acesso 05 abril 2019: http://www.theguardian.com/world/2014/mar/24/brazil-army-rio-slums-violenceworld-cup)

YOUNG, Michael \& WILLMOTT, Peter. Family and Kinship in East London. Berkeley, CA: University of California Press, 1992. 